\title{
AMIANTO NÃO! O MANEJO DAS TELHAS DE FIBROCIMENTO E PERSPECTIVAS PARA DESAMIANTIZAÇÃO NA UNIVERSIDADE FEDERAL DA BAHIA, EM SALVADOR-BAHIA
}

\author{
NO ASBESTOS! THE MANAGEMENT OF FIBROCEMENT TILES AND PERSPECTIVES FOR \\ DEAMIANTIZATION IN THE FEDERAL UNIVERSITY OF BAHIA, IN SALVADOR-BAHIA
}

Flávia Adorno Alves Landimaa, Cláudia de Oliveira D’Arêde ${ }^{a}$, Luiz Roberto Santos Moraesa

$\underline{\text { flavia.adorno.landim@gmail.com, claudiadared@gmail.com, moraes@ufba.br }}$

aUniversidade Federal da Bahia

Submissão: 11 de agosto de 2020

Aceitação: 26 de outubro de 2020

\section{Resumo}

Ao se estudar e analisar resíduos sólidos, nota-se a relação entre os aspectos ocupacionais, ambientais e de saúde. Os resíduos sólidos provenientes de materiais contendo amianto são comprovadamente nocivos, causando o adoecimento dos trabalhadores e culminando em uma questão de saúde pública. $O$ presente trabalho teve como objetivo analisar o manejo das telhas de fibrocimento contendo amianto e a existência de perspectivas de desamiantização nas instalações da Universidade Federal da Bahia em Salvador/BA. Tratase de um estudo do tipo exploratório com abordagem qualitativa em que a coleta de dados ocorreu por meio de entrevistas semiestruturadas com trabalhadores telhadistas, servidores, estudantes e professores dessa universidade e por meio do exame das legislações vigentes. A análise documental mostrou que os dispositivos legais e normativos identificados carecem de recursos e ações para serem implementados e que não há uma política de incentivo à desamiantização, assim como revelou a carência de áreas públicas para destinação final ambientalmente adequada do material contaminado e a falta de uma fiscalização apropriada. A pesquisa não identificou haver uma perspectiva de desamiantização na UFBA, apesar de ter constatado a existência de pessoas expostas ao risco invisível provocado pelo amianto. O estudo mostra um cenário de degradação ambiental e preocupante para a saúde coletiva, mas que também estimula a discussão de soluções e o desenvolvimento de novas pesquisas.

Palavras-chave: Resíduos sólidos perigosos; Amianto; Asbesto; Manejo

\section{Abstract}

When studying and analyzing solid waste, the relationship between occupational, environmental and health aspects is noted. Solid waste from materials containing asbestos is proven to be harmful, causing workers to become ill and culminating in a public health issue. The present work aimed to analyze the handling of asbestos-cement tiles and the existence of prospects for deactivation in the Federal University of Bahia facilities in Salvador / BA. This is an exploratory study with a qualitative approach in which data collection took place through semi-structured interviews with roofing workers, servers, students and professors at this university and through the examination of current legislation. The documentary analysis showed that the legal and normative provisions identified lack resources and actions to be implemented and that there is no policy to encourage deactivation, as well as the lack of public areas for the environmentally appropriate final disposal of contaminated material and the lack of adequate supervision. The research did not identify a prospect of deactivation at UFBA, despite having found the existence of people exposed to the invisible risk caused by asbestos. The study shows a scenario of environmental degradation and worrying for public health, but which also stimulates the discussion of solutions and the development of new research.

Keywords: Hazardous solid waste; Asbestos; Handling

\section{INTRODUÇÃO}

Largamente utilizado no mundo por muitas décadas, o amianto ou asbesto esteve contido no processo produtivo de diversos produtos, dentre eles: painéis planos; painéis corrugados empregados para cobertura na construção civil; fabricação de caixas d'água e tubulações de pressão, água e esgoto; revestimentos de parede; 
luvas e roupas de uso industrial resistentes ao fogo; e elementos de fricção de freios e embreagens e gaxetas utilizados em veículos (CASTRO; GIANNASI; NOVELLO, 2003). O amianto ou asbesto é uma fibra de origem mineral derivada de rochas que têm em sua composição silicatos hidratados de magnésio, ferro, cálcio e sódio. Podem ser encontradas até trinta variedades de amianto, mas apenas cinco ou seis foram mais usualmente comercializadas (CASTRO; GIANNASI; NOVELLO, 2003).

O grande interesse comercial em relação ao amianto se deve às suas propriedades, que incluem a resistência ao fogo (incombustível e isolante de calor em temperaturas moderadas), a resistência alta à abrasão mecânica e química, baixa condutibilidade elétrica, capacidade de isolamento acústico e baixo custo, tornando-o matéria-prima para a produção de diversos produtos (CASTRO; GIANNASI; NOVELLO, 2003).

A exposição ao conteúdo nocivo ocorre pela inalação das fibras dispersas no ar e pelo manuseio do material. A população exposta ao amianto inclui os trabalhadores da construção civil que fizeram uso de materiais (telhas, caixas d'água, entre outros) contendo essa fibra diretamente sem dispor da proteção adequada; os trabalhadores da mineração e do transporte da fibra e da manufatura e comercialização dos produtos que a contêm; as comunidades situadas próximas de jazidas ao ar livre; os trabalhadores do segmento de coleta, transporte e processamento de resíduos sólidos contendo amianto; os mecânicos do segmento automotivo; operários de várias indústrias que utilizam essa fibra no seu processo produtivo; funcionários de lojas de materiais de construção, bem como, de forma indireta, as famílias dos trabalhadores que mantêm contato com as roupas e os pertences expostos à substância no ambiente de trabalho.

No Brasil, a Norma Brasileira (NBR) da Associação Brasileira de Normas Técnicas (ABNT) que discorre sobre as diretrizes para 0 armazenamento adequado de resíduos sólidos perigosos é a ABNT no 12.235 (ABNT, 1992). No entanto, há um grande desafio para descarte de rejeitos contendo amianto quanto ao local de destinação, devido à carência de áreas preparadas para receber resíduos perigosos. No Brasil, não existem aterros industriais públicos de classe I (resíduos perigosos), e os aterros privados cobram valores elevados para receber o material. Além disso, a maioria destes últimos está concentrada nas regiões Sul e Sudeste. Essas dificuldades fazem com que os rejeitos do amianto sejam descartados juntamente com resíduos comuns e não perigosos.

Em 29 de novembro de 2017, no julgamento realizado pelo Superior Tribunal Federal (STF), os ministros declararam a inconstitucionalidade do artigo $2^{\circ}$ da lei federal $\mathrm{n}^{\circ}$ 9.055/1995 (BRASIL, 1995), que permitia o uso do amianto do tipo crisotila. Contudo, um mês depois, a Ministra Rosa Weber refez a decisão e tornou a lei válida somente nos estados onde já havia lei específica para esse banimento instituída. Além da Bahia, alguns estados proibiram 0 uso da fibra cancerígena, como: Santa Catarina, São Paulo, Rio de Janeiro, Minas Gerais, Rio Grande do Sul, Pernambuco, Mato Grosso do Sul e Amazonas, entre outros. Na Bahia, desde 2007 as associações de expostos ao amianto lutavam pela regulamentação de uma lei que proibisse a extração, produção e comercialização dessa fibra mineral no estado. A pressão de entidades ligadas à proteção dos trabalhadores e de movimentos sociais foi fundamental para a proibição total do uso do amianto, tornando a Bahia o $12^{\circ}$ estado brasileiro a banir o mineral, por meio da lei $\mathrm{n}^{\circ}$ 13.830, de 27 de dezembro de 2017 (BAHIA, 2017).

A utilização amianto em diversos materiais e setores foi massiva. Com o surgimento de inúmeros casos de doenças, seguido pela luta e banimento do mineral em diversos países do mundo e, tardiamente, no Brasil, realizaram-se estudos que demostraram o seu impacto nocivo para a saúde e fizeram surgir uma dúvida que ainda persiste: 0 que fazer com o material contendo amianto que é transformado em resíduo ou rejeito? Atualmente, um dos maiores entraves é como fazer o manejo seguro, incluindo desde a remoção até a destinação final, de estruturas antigas encontradas em obras com demolições ou desconstruções e que podem conter amianto.

Em 2004, foi aprovada a resolução no 348/2004 do Conselho Nacional de Meio Ambiente (Conama), que altera a resolução Conama $n^{\circ}$ $307 / 2002$ e inclui o amianto na classe de resíduos perigosos (BRASIL, 2002; 2004). Dessa forma, o item relativo a Classe $D$ de resíduos, passa a vigorar com a seguinte redação:

Art. 3․ São resíduos perigosos oriundos do processo de construção, tais como tintas, solventes, óleos e outros ou aqueles contaminados ou prejudiciais à saúde oriundos de demolições, reformas e reparos de clínicas radiológicas, instalações industriais e outros, bem como telhas e demais objetos e materiais que contenham amianto ou outros produtos nocivos à saúde (BRASIL, 2004, p.1).

Infelizmente, no âmbito da gestão pública as mudanças demandam tempo. Mesmo após o banimento do amianto, o Brasil pode experimentar nos próximos anos um aumento do número de casos de câncer e outras doenças associadas a esse mineral, bem como a elevação dos gastos em saúde e com a remediação dos resíduos dos 
produtos contendo a substância. $\mathrm{O}$ despejo apropriado de materiais/resíduos contendo amianto é importante não apenas para proteger a comunidade e o meio ambiente, como também para impedir o recolhimento e reutilização do material removido. A exposição ao amianto e materiais/resíduos que o contêm vai além da questão ambiental e deve ser considerada uma urgência sanitária, pelos riscos eminentes à saúde coletiva.

Diante da necessidade de mais estudos sobre o tema e da importância do conhecimento sobre o manejo de resíduos contendo amianto em uma instituição pública de ensino, este estudo analisou o manejo de telhas de fibrocimento contendo esse mineral $e$ as perspectivas de desamiantização nos campi da Universidade Federal da Bahia, em Salvador, contribuindo assim para uma possível mudança da realidade local.

\section{METODOLOGIA}

O trabalho consistiu em um estudo exploratório, com abordagem qualitativa, realizado com servidores, professores, estudantes e trabalhadores telhadistas terceirizados que atuam nos campi da Universidade Federal da Bahia (UFBA), em Salvador, Bahia.

A partir da análise dos resultados das entrevistas foram definidas as seguintes categorias: riscos ocupacionais, riscos ambientais, riscos à saúde e perspectiva de desamiantização; e as subcategorias: atividades realizadas nos telhados, condições para realização das atividades, fiscalização, manejo dos resíduos, conhecimento dos riscos à saúde, e identificação de desconfortos à saúde.

\section{Local de estudo}

A UFBA é uma instituição pública federal de ensino superior criada para desenvolver atividades de ensino, pesquisa e extensão de forma integrada à sociedade. A referida universidade foi escolhida para estudo por sua atuação relevante na produção de conhecimento científico e social, por disseminar um pensamento crítico, por realizar pesquisas de importância para o desenvolvimento da sociedade, pela oferta de serviços aos cidadãos, por abrigar uma população relativamente grande e possuir instalações antigas nas quais o amianto foi utilizado como matériaprima.

Dentre os setores dessa universidade, a Superintendência de Meio Ambiente e Infraestrutura (Sumai) é o responsável por planejar, coordenar e controlar o desenvolvimento da sua infraestrutura e do seu patrimônio físico, além de zelar pela manutenção das suas instalações físicas e seus espaços comuns, assim como elaborar, acompanhar e coordenar a implantação das políticas de gestão da instituição.

Todos os campi da UFBA juntos totalizam uma área coberta de 107.917,77 $\mathrm{m}^{2}$, com $90.113,26 \mathrm{~m}^{2}$ de cobertura em telha de fibrocimento (contendo amianto ou não), o que representa $83,50 \%$ de toda área de cobertura da universidade. Os outros $16,50 \%$ têm cobertura em telha cerâmica ou metálica (UFBA, 2019).

\section{População de estudo}

A população de estudo foi constituída por 15 (quinze) entrevistados. Optou-se pela seleção não probabilística intencional, considerando-se que esse número de participantes é suficiente para fornecer as informações necessárias sobre o tema da pesquisa. As entrevistas tiveram duração variada entre 6 (seis) a 45 (quarenta e cinco) minutos, foram realizadas por meio de gravação de áudio com uso de smartphone e mediante a assinatura do Termo de Consentimento Livre e Esclarecido (TCLE).

Inicialmente, foi previsto entrevistar 17 (dezessete) pessoas, sendo 5 (cinco) trabalhadores telhadistas, 4 (quatro) servidores da Sumai, 4 (quatro) professores e 4 (quatro) estudantes, mas a empresa prestadora de serviços de manutenção, reforma e construção só dispunha, no momento da pesquisa, de 3 (três) trabalhadores telhadistas atuando nas instalações da UFBA.

\section{Critérios de seleção dos participantes}

Para seleção dos trabalhadores atuantes em reformas e construção nos campi, levou-se em consideração aqueles que desenvolviam a função de telhadistas na empresa de construção, reforma e manutenção, com contrato vigente com a UFBA. Quanto aos servidores da Sumai, optou-se pelas coordenações que atuam nas construções e reformas dos prédios da universidade, seja no processo de concepção do projeto, na contratação de empresas terceirizadas ou na gestão ambiental, e que aceitaram participar do estudo, sendo as seguintes: Coordenação de Meio Ambiente; Coordenação de Planejamento, Projetos e Obras; e Coordenação de Manutenção Civil (incluindo reformas). $\mathrm{Na}$ seleção de professores da universidade, buscou-se, aleatoriamente, identificar profissionais de áreas distintas, com ou sem conhecimento sobre o tema, e que transitassem em campi diversos. Nessa mesma linha, foram selecionados os estudantes, sendo de cursos distintos, semestres variados (início, meio e em fase final de conclusão do curso), sem se considerar relevante um conhecimento prévio do tema.

\section{Etapas de desenvolvimento da pesquisa}


A pesquisa ocorreu em duas fases: pesquisa documental e pesquisa de campo. $\mathrm{Na}$ primeira fase, para exame da matéria, foi feita a pesquisa documental que incluiu a identificação de legislações, normas e manuais técnicos vigentes em território nacional e principalmente na localidade do estudo. Na segunda fase, visando conhecer a realidade do tema, foram realizadas entrevistas semiestruturadas com atores expostos ao manejo das telhas de fibrocimento contendo amianto existentes nos campi de Salvador e investigadas as perspectivas de desamiantização na Universidade Federal da Bahia.

$\mathrm{Na}$ pesquisa documental, foram verificados os métodos adequados para manejo dos resíduos sólidos contendo amianto relacionados em legislações, normas técnicas e regulamentadoras que oferecem subsídios para a gestão do resíduo objeto deste do estudo, com as formas seguras para manejá-lo e para a disposição ambientalmente adequada dos seus rejeitos.

A busca foi executada eletronicamente nas bases de dados de sites governamentais como o Portal da Legislação, Google Search e Associação Brasileira de Normas Técnicas (ABNT), por meio de termos como: resíduo perigoso, amianto e asbesto. Os critérios de seleção do material incluíram: serem documentos vigentes na esfera municipal, estadual ou federal, estarem indexados nas bases de dados eletrônicas consultadas e possuírem conteúdo que atendesse à temática proposta. Ficaram excluídos os textos que não atenderam ao objetivo proposto e aos critérios de seleção.

$\mathrm{Na}$ pesquisa de campo foram realizadas entrevistas semiestruturadas com a formulação de um roteiro que permitisse compreender as percepções de riscos relacionados à exposição no manejo das telhas de fibrocimento contendo amianto e identificar as perspectivas de desamiantização na UFBA em Salvador.

\section{Análise de dados}

A metodologia de análise dos conteúdos da pesquisa documental e bibliográfica, como fonte de informação, foi pautada na leitura, separação por fonte, tipo e sínteses. Posteriormente, os documentos analisados foram agrupados por categorias.

As entrevistas semiestruturadas foram gravadas e os dados obtidos foram transcritos e compilados utilizando-se a técnica de análise de conteúdo, que consiste em extrair, por meio de procedimentos sistemáticos e objetivos de descrição do material gravado, indicadores a partir dos quais se possam inferir conhecimentos relativos às condições de produção e recepção das mensagens gravadas (BARDIN, 2011). A adoção dessa técnica tem como objetivo analisar o que estava explícito nas falas dos entrevistados, codificar (salientar, classificar, agregar e categorizar) trechos das entrevistas transcritas, que são apresentadas em forma de um painel contendo a categoria (assunto abordado), subcategoria (perguntas formuladas nas entrevistas) e o registro (transcrição de trechos de fala relacionados às categorias). A categorização das falas dos entrevistados visa identificar os discursos, as diferentes concepções sobre um mesmo assunto e observar a frequência com que essas diferenças ocorrem.

A análise foi realizada considerando as categorias: riscos ocupacionais, riscos ambientais, riscos à saúde e perspectiva de desamiantização; e as subcategorias: atividades realizadas nos telhados, condições para realização das atividades, fiscalização, manejo dos resíduos, conhecimento dos riscos à saúde e identificação de desconfortos à saúde.

\section{Aspectos éticos}

A pesquisa foi aprovada e autorizada pelo Comitê de Ética em Pesquisa (CEP) da Faculdade de Medicina da Bahia (FMB) da Universidade Federal da Bahia (UFBA), conforme Resolução nำ 466, de 12 de dezembro de 2012, do Conselho Nacional de Saúde (BRASIL, 2013). Processo CAAE - Certificado de Apresentação de Apreciação Ética n. 17726419.7.0000.5577.

Os participantes receberam informações sobre o estudo que contemplam a justificativa, os objetivos e os procedimentos que foram utilizados na pesquisa, com o detalhamento dos métodos utilizados, esclarecimentos sobre riscos, minimização destes, garantia de sigilo e liberdade para deixar de participar da pesquisa a qualquer momento. Após concordância em participar, todos os entrevistados assinaram e receberam uma cópia de Termo de Consentimento Livre e Esclarecido (TCLE).

\section{RESULTADOS E DISCUSSÃO}

A proposta do desenvolvimento desta etapa do estudo foi descrever a percepção e compreensão dos atores envolvidos (servidores, trabalhadores, estudantes e professores) sobre 0 tema, os riscos do amianto e as perspectivas de desamiantização na UFBA, e agregar informações coletadas na bibliografia específica.

Os serviços que compõem a rotina dos trabalhadores terceirizados consiste em substituir telhas quebradas e madeiras apodrecidas de estruturas, limpar as peças e aplicar impermeabilizantes para evitar infiltrações. Especificamente na troca de telhas, podem ser utilizadas tanto telhas de fibrocimento, metálicas ou cerâmicas; em geral o tipo do material depende do que já compõe o telhado, em se tratando de 
manutenção.

Diariamente, a engenheira da empresa terceirizada faz a programação das atividades, dos locais e de quais equipes serão deslocadas. A empresa $X$ possui não só telhadistas atuando na UFBA, como também pedreiros, pintores etc. A Coordenação de Manutenção da Sumai recebe essa programação no início da manhã e toma conhecimento dos serviços a serem executados e em quais locais, para que possa fiscalizá-los.

\section{Categoria - Riscos ocupacionais}

O risco consiste na probabilidade de ocorrerem consequências indesejadas, sejam danos para a saúde e integridade física, moral ou financeira do cidadão, para o meio ambiente, a sociedade ou a empresa. A existência de probabilidade de um trabalhador sofrer algum dano resultante de suas atividades profissionais é denominada de risco ocupacional, ou seja, são acidentes ou doenças possíveis a que estão expostos os trabalhadores no exercício do seu trabalho ou por motivo da sua ocupação.

\section{Subcategoria - Condições para realização das atividades}

Os participantes telhadistas, quando questionados sobre as condições para realização das atividades nos telhados da UFBA, relataram receber Equipamento de Proteção Individual (EPI) e fardamento em tecido brim da empresa terceirizada em que atuam, juntamente com treinamento relacionado a trabalho em altura e acompanhamento com diálogo semanal de segurança sobre aspectos gerais da segurança do trabalho e saúde ocupacional. Quanto ao EPI, um dos telhadistas salientou que, quando ocorre de faltar algum dispositivo de proteção, tanto a UFBA quanto a terceirizada em que trabalham não obrigam os trabalhadores a realizar as atividades, não tendo eles a necessidade de se expor de forma compulsória. Dentre os dispositivos disponibilizados e citados pelos telhadistas estão: bota de couro, luva, capacete, máscara simples sem filtro, óculos e cinto de segurança. Os entrevistados demonstraram satisfação em relação aos EPI entregues, não expressando dúvidas se eles são adequados ou não aos riscos das atividades que executam e da exposição a materiais contendo amianto. Outro telhadista acrescentou a questão das ferramentas, alegando que são próprias e não fornecidas pela empresa em que trabalha, e que ele também não dispõe de uma forma adequada para transportá-las.

O Anexo no 12 da Norma Regulamentadora (NR) o 15 exige que o empregador forneça gratuitamente toda vestimenta de proteção que poderá ser contaminada por asbesto, não podendo esta ser utilizada fora dos locais de trabalho; assim como determina que o empregador deve se responsabilizar pela higienização e descontaminação dos fardamentos e dispor de vestiário duplo (uma instalação que oferece uma área para guarda de roupa pessoal e outra, isolada, para guarda da vestimenta de trabalho, ambas com comunicação direta com a bateria de chuveiros) para os trabalhadores expostos ao asbesto (BRASIL, 1991a; 1991b).

Assim, os dispositivos mínimos de proteção e segurança para manuseio de materiais ou resíduos contendo amianto deveriam incluir: macacão descartável com capuz, luvas, polainas e respirador (Fator de Proteção do Tipo P3), podendo ser higienizados, preferencialmente no banho juntamente com o trabalhador (GIANNASI, 2019). No Manual Prático para subsidiar a proposta para normatização da demolição, transporte e disposição final de resíduos de obras de construção civil (entulho) e outros materiais contendo amianto ou asbesto, Giannasi (2019, p. 1) considera que: "Caso o macacão não seja descartável, deverá ser contratado serviço de lavanderia, licenciado pelo órgão ambiental e/ou de saúde e cadastrado obrigatoriamente junto ao Ministério do Trabalho e Emprego", dispositivos e orientações que, parece, não estão sendo seguidas nos campi da UFBA.

O Manual Troca Limpa da Fiocruz (PEREZ, 2013) também traz uma contribuição à questão quando determina que, para proteção do trabalhador no manuseio do amianto, deve-se utilizar equipamentos de proteção individual, como: máscara com fator de proteção do tipo P3; macacão com ajuste nos punhos e tornozelos incluindo capuz; capacete; luvas de material não poroso e resistente a abrasão, cortes, rasgos e produtos químicos; óculos com vedação; botas preferencialmente lisas e com solado antiderrapante; e que, terminado o trabalho, a máscara e o macacão sejam descartados ou higienizados, sob a responsabilidade do empregador, para evitar a propagação de fibras de amianto no ambiente. O manual traz ainda explicações sobre o modo de utilização dessas proteções, as formas mais seguras de colocá-las, retirá-las e de fazer a sua higienização (PEREZ, 2013). Esse manual também reafirma o que Giannasi (2019) apresenta sobre necessidade de o empregador disponibilizar, obrigatoriamente, um vestiário duplo para os trabalhadores (PEREZ, 2013). As especificações de construção e instalação do vestiário devem obedecer às determinações da NR 15, Anexo 12 (PEREZ, 2013). Segundo o citado manual (PEREZ, 2013, p.18), o vestiário duplo deve ser usado somente para os trabalhadores que estiverem expostos ao amianto, devendo ser constituído por três unidades:

1. Unidade suja: onde os trabalhadores entram com os EPIs contaminados pelo amianto e os descartam nas bombonas 
de lavagem ou descarte. As bombonas devem estar etiquetadas conforme regulamentação dos produtos que contenham amianto. - Bombona para lavagem: óculos, bota, luva e capacete; Bombona para descarte: máscara respiratória, e macacão.

2. Unidade de descontaminação: bateria de chuveiros onde os trabalhadores entram sem o macacão.

3. Unidade limpa: onde os trabalhadores se vestem com a roupa pessoal.

As determinações da NR $n^{\circ} 15$ decorrem do fato de que as vestimentas e ferramentas que os trabalhadores expostos ao amianto levam para casa contêm amianto, e, consequentemente, muitos familiares desses trabalhadores são contaminados, como foi constatado por D'Arêde (2009) em seu estudo envolvendo as viúvas e extrabalhadores da mina de São Félix, em Bom Jesus da Serra na Bahia. A autora encontrou significância na contaminação atestada nesses sujeitos. Assim, estudos mostram que as mulheres e crianças passaram a ser consideradas trabalhadores indiretos e também vulneráveis ao adoecimento em decorrência do manuseio de roupas e objetos dos trabalhadores expostos ( $D^{\prime}$ AREDE, 2009; MENDES, 2001).

Todos esses dispositivos e orientações supracitados necessitam ser considerados pela UFBA e pelas empresas contratadas, visando proteger a saúde dos trabalhadores envolvidos e de suas famílias.

Quanto à comunicação dirigida aos servidores da Sumai/UFBA sobre os riscos do material/resíduo e os treinamentos e dispositivos de proteção adequados aos trabalhadores expostos diretamente, todos abordaram a responsabilidade da empresa contratada em prover as condições de segurança para os telhadistas, em conformidade com os requisitos legais vigentes. Os entrevistados demonstraram não saber ao certo como se dá o processo de contaminação e declararam que a comprovação de que as proteções adequadas são entregues não é exigida, também não souberam dizer de forma assertiva de quem é a obrigação de entregálas.

A fala de um dos servidores da Sumai, quando cita que as telhas de fibrocimento não estavam no radar dessa superintendência como algo prejudicial e que isso requer inúmeras ações preventivas e protetivas, leva à discussão sobre a invisibilidade dos riscos que o uso do material traz aos expostos. Em outro momento, os telhadistas foram questionados sobre algum tipo de telha com o qual eles têm preferência para trabalhar, e as afirmações demonstraram preferência em manusear a telha de fibrocimento, por serem peças inteiras e maiores, ou as que não são pesadas e que sejam de material mais acessível, como as telhas coloniais.

A telha de fibrocimento contendo amianto foi amplamente utilizada no mundo todo, justamente por suas características atrativas, dentre elas 0 baixo custo e a praticidade na instalação. A preferência dos trabalhadores pela sua utilização reafirma o risco invisível a que os telhadistas estão expostos; mesmo sendo altamente nocivo à saúde, este material ainda é visto como vantajoso de certo de modo.

\section{Subcategoria - Fiscalização}

Quando questionados sobre a exigência pela UFBA do atendimento a critérios de meio ambiente, saúde ocupacional e segurança do trabalho estabelecidos antes da contratação, e da fiscalização por parte da instituição durante a prestação dos serviços contratados, os entrevistados, três servidores da Sumai, relataram que no edital e termo de referência são listadas legislações ambientais (resíduos, sustentabilidade e poluição), inclusive para que o processo licitatório seja aprovado pelo Tribunal de Contas da União (TCU). Em relação à saúde ocupacional, apenas um entrevistado abordou o tema, explicitando que, em contratos referentes a obras, acredita que não sejam exigidos exames e atestado de saúde ocupacional em razão dos riscos a que os trabalhadores estarão expostos, mas revelou que em contratos de manutenção, quando eles recebem a equipe de mão de obra, os exames devem ser apresentados. Quanto à segurança do trabalho, um dos entrevistados acredita que $o$ edital e contrato firmado com a terceirizada preveem o atendimento à legislação e às normas regulamentadoras, o uso de EPI e um técnico de segurança do trabalho da contratada acompanhando a execução dos serviços.

Os entrevistados servidores da Sumai demonstraram não ter um conhecimento preciso sobre como se dá o processo de fiscalização das contratadas antes do início das atividades e quais requisitos/diretrizes de meio ambiente, segurança do trabalho e saúde ocupacional da instituição devem ser atendidos. A lei $n^{\circ}$ 13.429/2017, que altera a lei no 6.019/1974 e dispõe sobre as relações de trabalho na prestação de serviços por terceiros, em seu artigo $9^{\circ}, \S 1^{\circ}$, determina que: "É responsabilidade da empresa contratante garantir as condições de segurança, higiene e salubridade dos trabalhadores, quando o trabalho for realizado em suas dependências ou em local por ela designado" (BRASIL, 2017, s.p.). Para que essas condições sejam asseguradas, é necessário que esteja evidenciado institucionalmente, em todos os editais, contratos e termos de prestação de serviço, os requisitos a serem atendidos e que as empresas contratadas evidenciem, periodicamente, $\mathrm{o}$ atendimento por meio de 
documentos comprobatórios. Especificamente para a prestação de serviços que envolvem exposição a materiais/resíduos perigosos como o amianto, é necessária a comunicação dos riscos aos expostos, a capacitação para manejo do material/resíduo de forma segura e a disponibilização de dispositivos de segurança e de todas as medidas protetivas, sejam elas individuais ou coletivas, exames ocupacionais específicos realizados periodicamente e acompanhamento dos expostos anos após a exposição.

Sobre a fiscalização durante a execução dos serviços contratados com as terceirizadas, um dos entrevistados da Sumai afirma que a empresa terceirizada tem um técnico de segurança do trabalho que acompanha principalmente serviços mais complexos como os executados em telhados. Os servidores afirmam que há uma equipe gestora da Sumai que fiscaliza a execução dos contratos quanto à qualidade dos serviços, às relações de trabalho, à utilização de EPI e ao manejo de resíduos.

Ainda sobre o processo de fiscalização, um servidor da Sumai relatou que as terceirizadas diariamente enviam no início da manhã a programação do dia e que esta é a forma do fiscal ter conhecimento de onde os trabalhadores terceirizados estão atuando e dos serviços que estão sendo executados. O servidor relata também as dificuldades da área de manutenção da UFBA para fiscalizar as contratadas devido à carência de recursos decorrentes de cortes do Governo Federal para as universidades públicas e de outros motivos que incluem a falta de veículo para 0 deslocamento às frentes de serviço, poucos servidores para atuar na fiscalização, extensão das áreas dos campi, que são equivalentes a uma cidade, entre outros.

Sob a ótica dos trabalhadores telhadistas da empresa terceirizada de manutenção $X$, a fiscalização da UFBA não é rotineira e não tem seu foco nas condições de trabalho, estando mais voltada para as etapas de execução dos serviços. A verificação das condições de saúde ocupacional e segurança do trabalho, segundo os trabalhadores, é feita somente pelo técnico de segurança da empresa $X$. Isso se contrapõe aos relatos dos servidores da Sumai, que afirmam haver uma equipe da UFBA atuando na fiscalização, inclusive com a presença de um engenheiro de segurança do trabalho.

\section{Categoria - Riscos ambientais}

\section{Subcategoria - Manejo dos resíduos}

Quando tentou-se captar dos servidores da Sumai entrevistados informações sobre a existência de um Plano Gerenciamento de Resíduos Sólidos (BRASIL, 2010) - incluindo aqueles contendo amianto - gerados nas atividades de manutenção, reforma e construção, eles não souberam descrever exatamente como se dá a concepção do plano, de que forma ele é elaborado nem quem é responsável por elaborálo. Acreditam que seja uma demanda da Coordenação de Meio Ambiente. A Coordenação de Meio Ambiente, por sua vez, afirmou que sua área fornece um modelo de plano para as empresas terceirizadas e que, quando estas são contratadas para os serviços, devem entregar um plano elaborado a partir do documento fornecido pela Sumai. Não há um consenso entre os entrevistados quanto à existência de um Plano de Gerenciamento de Resíduos Sólidos, seja um plano da própria universidade, incluindo os resíduos gerados nas atividades executadas pelas contratadas, ou planos particulares elaborados por cada empresa.

Quando questionados sobre a metodologia adotada para remoção de resíduos perigosos, incluindo as telhas contendo amianto, os três entrevistados deram respostas distintas. Um deles acredita que pela existência de uma legislação que baniu o amianto da Bahia e do Brasil, o assunto havia sido superado. Outro acredita que as construções de obras não gerem resíduos perigosos, imaginando que os EPI são suficientes para proteção dos expostos e que, caso haja algum resíduo perigoso, eles acionam a Coordenação de Meio Ambiente. E por fim, o terceiro entrevistado, um servidor da Sumai, salientou as dificuldades em fiscalizar a remoção de resíduos e que, na maior parte das vezes, essa atividade é feita de forma independente pela empresa terceirizada.

A bibliografia específica considera que a etapa de remoção das telhas de fibrocimento contendo amianto precisa ser muito bem acompanhada e fiscalizada, de modo que todas as normas técnicas e resoluções ambientais sejam obedecidas. A via de exposição mais agressiva em se tratando de amianto ocorre pela inalação das fibras dispersas no ar, por isso a remoção deve ser realizada de forma a minimizar essa dispersão (PEREZ, 2013). Assim, para limitar o desprendimento de poeira com as fibras, as telhas contendo amianto devem ser retiradas da forma mais íntegra possível, utilizando-se cordas, evitando deixá-las cair ou quebrar em pedaços e preferencialmente umedecendo 0 material (GIANNASI, 2019).

Outra contribuição é disponibilizada pelo Manual Troca Limpa da Fiocruz (PEREZ, 2013), que sugere que, para uma remoção segura das telhas de fibrocimento contendo amianto, devem ser seguidas algumas etapas como: elaboração e execução do plano de remoção dos materiais com amianto; colocação de lona plástica no interior do ambiente (sobre os móveis, eletrodomésticos, piso etc.) para proteção contra as fibras de amianto que podem se desprender no ar no momento da retirada das telhas; uso dos Equipamentos de 
Proteção Individual (EPI); retirada cuidadosa das telhas (dois ou mais trabalhadores), com ajuda de andaimes e cordas, para que elas não se quebrem ou quebrem o mínimo possível.

$$
\text { Quanto à segregação e ao }
$$

acondicionamento de resíduos, os servidores da Sumai demonstraram desconhecimento sobre o tema e revelam a falta de uma diretriz a ser seguida pelas coordenações e repassada às contratadas. Os entrevistados acreditam que não haja segregação em relação aos demais materiais da construção civil. Uns disseram não saber se existem resíduos de telhas de fibrocimento contendo amianto. Outros acreditam que a segregação e o acondicionamento dos resíduos são realizados pela empresa terceirizada ou que, se essas telhas ainda estiverem em bom estado, podem estar sendo guardadas para uso em outro momento. Alguns não souberam dizer como se dá o processo. Por outro lado, os trabalhadores da empresa $X$ relataram que quebram o material, depois ensacam e jogam em uma caçamba e que desconhecem como são transportados e para qual destino.

Para evitar a dispersão das fibras por meio da quebra das telhas, é recomendável que as peças inteiras sejam embaladas em plástico resistente, cintadas e dispostas sobre pallets (PEREZ, 2013). No caso de haver telhas quebradas, a recomendação é que sejam acondicionadas em big bags (PEREZ, 2013). Após o acondicionamento e até que sejam transportados para descarte, os pallets e big bags devem ser armazenados em local isolado e coberto para preservação das embalagens (PEREZ, 2013).

Segundo Giannasi (2019), as embalagens de telhas/resíduos contendo amianto devem estar etiquetadas conforme item 9.1 do Anexo 12 da NR 15 , de forma que quem for manejá-las tenha ciência do que elas contêm e de que a inalação da poeira do material embalado é nociva à saúde.

Quando questionados sobre o descarte, considerando o transporte e a destinação, os entrevistados servidores da Sumai informaram que os contratos preveem que operar o transporte e a disposição final ambientalmente adequada dos resíduos/rejeitos compete às contratadas, sendo necessário um aterro licenciado, ao qual elas devem apresentar os documentos comprobatórios no ato de entrega e medição dos serviços executados.

As telhas de fibrocimento contendo amianto, quando removidas, devem ser transportadas segundo as normas da Agência Nacional de Transporte Terrestre (ANTT) e da Polícia Rodoviária Federal (PRF) para cargas perigosas, que incluem as placas de sinalização na carroceria do caminhão com código internacional, ficha de emergência, cobertura da carroceria com material resistente, entre outros (GIANNASI, 2019).

Os resíduos contendo amianto devem atender a determinação do Conama, que por meio da Resolução n 348/2004, classifica os resíduos provenientes da construção civil na Classe D6, isto é, como perigosos (BRASIL, 2004). Por essa razão devem ser destinados a aterros para lixos perigosos (Classe I), licenciados pelo órgão ambiental estadual ou regional e cadastrados no Ministério do Trabalho e Emprego, conforme determina o Anexo 12 da NR-15 - Atividades e Operações Insalubres (BRASIL, 1991b).

\section{Categoria - Riscos à saúde}

Os riscos e as doenças atribuídas à exposição ao amianto são diversos, dentre elas a asbestose, que pode levar à morte por insuficiência respiratória, e as neoplásicas, ou cancerígenas, que podem atingir vários órgãos, a exemplo, o mesotelioma, tipo de câncer agressivo e incurável.

\section{Subcategoria - Conhecimento dos riscos à saúde}

Quando questionados sobre o entendimento do que é amianto/asbesto, nenhum dos entrevistados soube definir de forma mais técnica do que se trata e quais são as suas tipificações. Dos quinze entrevistados, sete deles relacionaram a exposição ao mineral com o desenvolvimento de câncer, demonstrando ser este o conhecimento mais comum entre eles, embora desconhecessem a fatalidade dessa contaminação. Alguns citaram materiais como as telhas e caixas d'água que contêm o mineral.

Quanto aos riscos que o amianto oferece e quais seriam, onze dos quinze entrevistados citaram o câncer como um dano causado à saúde dos expostos. Dentre os quatro que não citaram o câncer como um dano, três eram estudantes. Um dos estudantes afirmou não saber ao certo do que se trata e que não saberia informar se o amianto é bom ou ruim. Os demais citaram riscos respiratórios e dermatológicos ou que o amianto oferece riscos à saúde, mas não sabiam quais eram.

O amianto é a fibra com mais estudos realizados no que tange à relação com a saúde humana (FERRANTINI; FERREIRA JR.; FARIAS, 1988). Um estudo que objetivava examinar as tendências de mortalidade do mesotelioma e o câncer de pleura no Brasil e estimar carga futura de mortalidade dos expostos concluiu que 0 mesotelioma, considerado um tipo de câncer raro, é o que tem a maior incidência, representado $80 \%$ dos casos (ALGRANTI et al., 2015). Mesmo sendo o tipo mais incidente, essa incidência ainda é considerada baixa em razão do período de latência, das diferenças nos perfis econômicos regionais e da falta de conscientização por parte dos profissionais de saúde para suspeitar e identificar a doença (ALGRANTI et al., 2015). O 
estudo afirma ainda que a verdadeira magnitude da epidemia de mesotelioma em nível global ainda é desconhecida e que a doença não está desaparecendo, havendo previsão de um pico na próxima década (ALGRANTI et al., 2015).

Um dos professores entrevistados abordou a questão do período longo de latência das doenças ocasionadas pelo amianto, que é uma das barreiras para estabelecer o nexo entre a exposição à substância e o aparecimento da doença, e assegurar direitos aos trabalhadores adoecidos.

Dentre os entrevistados, apenas um citou o desenvolvimento de câncer em outros órgãos que não o pulmão, como câncer de intestino e estômago.

Dentre as doenças conhecidas que decorrem da exposição ocupacional estão a pneumoconiose, também denominada asbestose, e a formação de placas pleurais. Além dessas, a fibra do amianto também está associada ao câncer de laringe e câncer de ovário (IARC, 2012).

\section{Subcategoria - Identificação de desconfortos à saúde}

Os professores, estudantes e trabalhadores terceirizados foram questionados sobre desconfortos à saúde em razão da exposição à substância durante serviços de manutenção, reforma e construção ou a resíduos provenientes destes. A preocupação quanto à exposição foi demonstrada, mas nenhuma ocorrência específica de desconforto relacionada ao amianto foi citada. Os professores citaram desconfortos à saúde ocasionados por serviços de reforma, mas nenhum relacionado aos telhados e telhas de cimento amianto.

Os estudantes entrevistados disseram não ter presenciado ou notado reformas nos telhados. Os trabalhadores da empresa de manutenção entrevistados que atuavam especificamente nos telhados relataram desconfortos à saúde causados por fatores como mofo, uso de prime à base de óleo, calor, mas não foram precisos em informar sobre sintomas relacionados diretamente ao manuseio das telhas contendo o amianto.

A via de exposição ao amianto considerada como mais crítica é a respiratória, ou seja, pela inalação da poeira mineral dispersa no ar. Fatores como a intensidade e duração da exposição, a interação com outros fatores e a vulnerabilidade do organismo de cada indivíduo contribuem de forma mais ou menos intensa para o desenvolvimento das doenças (BRASIL, 2001). Por se tratar de uma doença de etiologia complexa, há uma enorme dificuldade em se estabelecer o nexo causal com - trabalho quando da ocorrência de casos suspeitos (BRASIL, 2001).

Para o diagnóstico clínico das doenças associadas ao amianto, primeiramente tenta-se relacionar o histórico ocupacional do paciente, o período de latência, os sintomas e as alterações nos exames de imagem realizados, provas de funções, exames citológicos e outros estudos laboratoriais (BRASIL, 2001). No entanto, uma anamnese criteriosa deve incluir também a investigação não apenas do histórico profissional, mas também de hábitos ou atividades de lazer do trabalhador que possam indicar a existência de nexos etiológicos importantes para o diagnóstico (COSTA; FERREIRA JR., 1984). Por fim, pelo longo tempo de latência das doenças associadas ao asbesto, os seus diagnósticos são, com frequência, efetuados após a demissão ou aposentadoria do trabalhador. Todos esses fatores tornam ainda mais difícil identificar que a doença esteja associada ao asbesto e faz com que ela seja categorizada como comum (não laboral), não sendo a sua causa atribuída ao trabalho.

\section{Categoria - Perspectivas de desamiantização}

A desamiantização consiste na retirada $e$ eliminação de materiais contendo amianto dos ambientes, o que exige um planejamento que contemple todas as medidas protetivas necessárias, que garantam que não haverá dispersão e contaminação do pessoal envolvido e do meio ambiente.

Quando foi abordado o conhecimento dos entrevistados sobre a existência de projeto para desamiantizar as instalações da UFBA, nenhum dos quatro servidores disse ter sido informado a respeito, tendo sido despertados para o assunto a partir do convite para participação nas entrevistas e apresentação do tema da presente pesquisa. Um dos entrevistados relatou que, pelo fato de existir uma lei de banimento do amianto no âmbito estadual e federal, essa temática era uma questão já superada, que não carecia de mais discussões e ações. Além disso, afirmou que não há uma política ou um documento institucionalizado que trate da desamiantização, mas que há uma prática implantada a partir de 2013 em novos pregões de manutenção, reforma e compra de material que proíbe a aquisição de materiais contendo amianto, o que vem ocasionando desde então a substituição paulatina desse material.

Sobre o processo de contratação de empresas que realizam serviços nos telhados da UFBA, um dos servidores entrevistados reafirma a eliminação do amianto nos últimos anos, explicando que a realização de toda compra de material e contratação de serviços passa pelo crivo da Procuradoria Federal, que analisa o processo, o atendimento a legislação vigente, e que, certamente, os materiais contendo amianto seriam vetados. Mas também afirma que esse tema não estava no horizonte das pautas da Sumai. Cabe ressaltar que na pesquisa documental realizada não foi identificada nenhuma legislação, municipal, 
estadual ou federal que aborde o pós-banimento, ou seja, ações, responsabilidades e prazo para retirada dos materiais contendo amianto já aplicados, inclusive nas instituições públicas.

\section{CONCLUSÃO}

A pesquisa documental revelou que os dispositivos legais e normativos identificados, apesar de apresentarem diretrizes para manejo dos materiais/resíduos sólidos perigosos, desde a sua remoção até a destinação final ambientalmente adequada, e de determinarem responsabilidades e sanções, na prática, carecem de recursos e ações para implementá-las, de definição de metodologias mais específicas de manejo e de fiscalização adequada.

Contrariando as exigências legais e normativas, observam-se falhas por parte do poder público. A pesquisa constatou: falta de divulgação de informações para a população quanto à periculosidade dos resíduos; não atuação dos órgãos ambientais responsáveis pela fiscalização de todas as etapas do manejo, desde a remoção até o transporte municipal e estadual desses resíduos; inexistência de uma política de incentivo à desamiantização para que materiais perigosos sejam substituídos, até mesmo nas instituições federais que têm esse tipo de material aplicado; e carência de áreas públicas para disposição final ambientalmente adequada de materiais/resíduos tóxicos como o amianto.

Em relação à percepção dos atores envolvidos sobre os riscos ocupacionais, as condições para realização das suas atividades não atendem ao que está disposto na legislação e normas regulamentadoras de saúde e segurança do trabalho. Os trabalhadores não recebem 0 conjunto de EPI necessário para minimizar os impactos do manejo das telhas de fibrocimento contendo amianto; relataram utilizar ferramentas próprias que muitas vezes são levadas para residência deles juntamente com o pó da fibra, estendendo a exposição aos familiares. Ainda assim, eles demonstraram satisfação pelo fato de a empresa em que trabalham contratada pela UFBA fornecer EPI, explicitando 0 desconhecimento dos riscos aos quais estão expostos. Os dispositivos de segurança aos expostos, como já apresentado, vão muito além do fornecimento de EPI e devem incluir também dispositivos de proteção coletiva, treinamento para manejo adequado do material, comunicação sobre os riscos, monitorização periódica da saúde ocupacional e fiscalização frequente. Nesse aspecto da fiscalização, por questões orçamentárias, em consequência da carência de recursos, e até mesmo por desconhecimento do tema amianto na atualidade, não há uma atuação dos servidores da Sumai nas frentes de serviço com olhar para a saúde ocupacional e a segurança dos trabalhadores.

Quando questionados sobre os riscos ambientais, na abordagem sobre o manejo dos materiais/resíduos contendo amianto, os servidores indicaram que o contrato com as terceirizadas determina todas as obrigações, contudo a UFBA não acompanha o atendimento contratual de forma efetiva. Desde a remoção das telhas, acondicionamento, incluindo embalagem, armazenamento e identificação, até o transporte e a destinação final adequada, que são as etapas do manejo de resíduos, não há atendimento ao que determinam as legislações vigentes. Parte dos servidores afirmou que é solicitado um Plano de Gerenciamento de Resíduos das contratadas, mas o plano em si não garante a gestão no dia a dia se não houver a evidência e o acompanhamento de sua implementação.

No que se refere à percepção de riscos à saúde, o conceito do que é amianto e o conhecimento dos riscos que ele acarreta, alguns entrevistados relacionaram o mineral às caixas d'água e telhas e indicaram de forma incipiente as doenças cancerígenas como o conceito de risco mais difundido entre eles. Nenhum deles relatou desconfortos para a saúde relacionados à exposição ao amianto até o encerramento da pesquisa.

Durante as entrevistas, quando questionados sobre as perspectivas de desamiantização e a existência de um projeto ou política institucional sobre o tema, os servidores da Sumai manifestaram desconhecimento sobre qualquer ação nesse sentido, mostraram certa acomodação em razão do material ter sido banido, sem considerar a questão dos materiais contendo o mineral já aplicados nas instalações e que ainda são fonte de risco ocupacional, ambiental e à saúde.

Mesmo que venham sendo substituídos de forma paulatina por outros materiais, quando da manutenção, reforma ou construção das unidades, já que os pregões não aceitam mais a compra de materiais com especificação contendo amianto, a maioria expressiva dos entrevistados acredita na presença dele nas instalações da UFBA em Salvador. Diante de outras dificuldades citadas pelos entrevistados para gestão de resíduos, fiscalização dos serviços etc., a desamiantização das instalações também deve enfrentar desafios pela falta de uma política com esse propósito no âmbito governamental, assim como pelas restrições orçamentárias, já que a universidade tem enfrentado, desde 2019, cortes de verbas pelo Governo Federal.

Quanto às limitações do estudo, ressalta-se que os resultados obtidos na pesquisa documental são restritos ao estado da Bahia e ao município de Salvador, assim como os dados das entrevistas estão restritos a Universidade Federal da Bahia, em Salvador, o que não permite sua extrapolação 
para a realidade dos demais campi e municípios brasileiros. Outra limitação envolve a dificuldade em acessar todo o arcabouço legal e normativo em uma única fonte, pelo fato de que ele se encontra distribuído em vários órgãos da Administração Pública, havendo, por essa mesma razão, conteúdos repetitivos. Com isso, é possível que algum documento não tenha sido consultado e analisado.

Por sua vez, foi adotado o tipo de entrevistas semiestruturadas, com questões abertas, informalidade e flexibilidade. Isso, alguma forma, pode não ter permitido uma resposta exata para a questão levantada, ocasionando um distanciando do tema proposto.

O método qualitativo mostrou-se importante para a pesquisa, pois apesar da relevância dos estudos quantitativos sobre materiais e resíduos sólidos, a identificação de requisitos legais e o processo de trabalho captando a percepção dos trabalhadores, servidores, professores e estudantes com as suas subjetividades podem contribuir para consolidação do conhecimento sobre o tema. A temática do amianto na trajetória da identificação dos riscos e desfechos e na trajetória do banimento já foi amplamente pesquisada, mas poucos ou quase nenhum estudo aborda a problemática da desamiantização. Portanto, tornam-se necessários mais estudos sobre este tema para maior difusão do conhecimento, avaliação do processo e identificação de propostas para um manejo seguro. Nesse contexto, é imprescindível recomendar que a UFBA elabore um plano de desamiantização e um plano de gerenciamento dos materiais/resíduos contendo amianto, capacitando todos aqueles que estão expostos de forma direta e as terceirizadas que realizem atividades de manutenção e reforma, considerando que a universidade não adquire materiais com especificação que inclua amianto desde 2013 e que, portanto, nas atividades de construção não há contato com esse material, exceto em ato de demolição de estrutura existente.

Por fim, conclui-se que este estudo apresenta um cenário preocupante para a saúde e o meio ambiente, mas estimula a discussão de soluções e o desenvolvimento de novos trabalhos explorando as particularidades das universidades públicas e ampliando a pesquisa no contexto nacional. A disposição ambientalmente inadequada de materiais/resíduos sólidos contendo amianto contribui significativamente para a continuação das desigualdades sociais, ameaça à saúde coletiva e contribui para o crescimento progressivo da degradação ambiental.

\section{REFERÊNCIAS}

ALGRANTI, E.; SAITO, C. A.; CARNEIRO, A. P. S.; MOREIRA, B.; MENDONÇA, E. M. C.; BUSSACOS, M.
A. The next mesothelioma wave: Mortality trends and forecast to 2030 in Brazil. Cancer Epidemiology, v. 39, n. 1, p. 687-692, oct. 2015.

ASSOCIAÇÃO BRASILEIRA DE NORMAS TÉCNICAS. NBR 12235: Armazenamento de resíduos sólidos perigosos. Rio de Janeiro: ABNT, 1992.

BAHIA. Lei no 13.830, de 27 de dezembro de 2017. Dispõe sobre a proibição da extração, comercialização e uso de amianto no Estado da Bahia. Diário Oficial [do] Estado [da] Bahia. Salvador, BA, 27 dez. 2017.

BARDIN, L. Análise de conteúdo. São Paulo: Edições 70, 2011.

BRASIL. Conselho Nacional de Saúde. Resolução no 466, de 12 de dezembro de 2012. Aprova diretrizes e normas regulamentadoras de pesquisas envolvendo seres humanos. Diário Oficial [da] República Federativa do Brasil. Brasília, DF, 13 jun. 2013. Disponível em: <http://www.conselho.saude.gov.br/resolucoes/2012/Re so466.pdf>. Acesso em: 11 abr. 2019.

BRASIL. Decreto № 126, de 22 de maio de 1991. Promulga a Convenção no 162, da Organização Internacional do Trabalho - OIT, sobre a utilização do asbesto com segurança. Diário Oficial [da] República Federativa do Brasil, Poder Executivo, Brasília, DF, 23 maio 1991a. Seção 1, p. 9778-9780.

BRASIL. Decreto no 7.404, de 23 de dezembro de 2010. Regulamenta a Lei no 12.305 de 2 de agosto de 2010, que institui a Política Nacional de Resíduos Sólidos, cria o Comitê Interministerial da Política Nacional de Resíduos Sólidos e o Comitê Orientador para a Implantação dos Sistemas de Logística Reversa, e dá outras providências. Diário Oficial [da] República Federativa do Brasil, Poder Executivo, Brasília, DF, 23 dez. 2010. p.1. (Edição extra).

BRASIL. Lei no 9.055, de 1 de junho de 1995. Disciplina a extração, industrialização, utilização, comercialização e transporte do asbesto/amianto e dos produtos que o contenham, bem como as fibras naturais e artificiais, de qualquer origem, utilizadas para o mesmo fim e dá outras providências. Diário Oficial [da] República Federativa do Brasil, Poder Executivo, Brasília, DF, 2 jun. 1995. p. 23371.

BRASIL. Lei no 13.429, de 31 de março de 2017. Altera dispositivos da Lei n o 6.019, de 3 de janeiro de 1974, que dispõe sobre o trabalho temporário nas empresas urbanas e dá outras providências; e dispõe sobre as relações de trabalho na empresa de prestação de serviços a terceiros. Diário Oficial [da] República Federativa do Brasil, Poder Executivo, Brasília, DF, 2017.

BRASIL. Ministério da Saúde. Organização PanAmericana da Saúde (Brasil). Doenças relacionadas ao trabalho: manual de procedimentos para os serviços de saúde. Organizado por Elizabeth Costa Dias. Colaboradores Idelberto Muniz Almeida et al. Brasília, DF, Ministério da Saúde, 2001. 508 p. (Série A. Normas e Manuais Técnicos, n. 114). 
BRASIL. Ministério do Meio Ambiente. Conselho Nacional do Meio Ambiente. Resolução no 307, de 5 de julho de 2002. Estabelece diretrizes, critérios e procedimentos para a gestão de resíduos da construção civil. Diário Oficial [da] República Federativa do Brasil, Brasília, DF, 17 jul. 2002. p. 9596.

BRASIL. Ministério do Meio Ambiente. Conselho Nacional do Meio Ambiente. Resolução no 348, de 16 de agosto de 2004. Altera a Resolução CONAMA no 307/2002, incluindo o amianto na classe de resíduos perigosos. Diário Oficial [da] República Federativa do Brasil, Brasília, DF, 16 ago. 2004.

BRASIL. Ministério do Trabalho e da Previdência Social. Secretaria Nacional do Trabalho. Portaria SSST $\mathrm{n}^{\circ}$ 01, de 28 de maio de 1991. Altera o Anexo no 12, da Norma Regulamentadora ํㅡ 15, que institui os "limites de tolerância para poeiras minerais" - asbestos. NR 15 - Atividades e operações Insalubres, poeiras minerais. Anexo 12. Diário Oficial [da] República Federativa do Brasil, Brasília, DF, 29 maio 1991b. Disponível em: <https://enit.trabalho.gov.br/portal/images/Arquivos_SS T/SST_NR/NR-15-atualizada-2019.pdf>. Acesso em: 11 abr. 2019.

CASTRO, H.; GIANNASI, F.; NOVELLO, C. A luta pelo banimento do amianto nas Américas: uma questão de saúde pública. Ciências \& Saúde Coletiva, Rio de Janeiro, v. 8, n. 4, p. 903-911, 2003.

COSTA, J. L. R.; FERREIRA JÚNIOR, Y. M. As doenças relacionadas ao asbesto (amianto). Revista Brasileira de Saúde Ocupacional, São Paulo, v.12, n. 47, p.21-30, jul./set.1984.

D' AREDE, C. O. O tempo das águas e dos ventos: significações do asbesto atribuídas às viúvas e extrabalhadores da mina de São Félix em Bom Jesus da Serra, Bahia, Brasil. 2009. 179f. Dissertação (Mestrado em Saúde, Ambiente e Trabalho) - Faculdade de Medicina da Bahia, Universidade Federal da Bahia,
Salvador, 2009.

FERRANTINI, V.; FERREIRA JR., E. A.; FARIAS, C. C. As tendências atuais no uso do asbesto no Brasil. Revista Brasileira de Saúde Ocupacional, São Paulo, n. 16, p.80-81, 1988.

GIANNASI, F. Manual prático para subsidiar proposta para normatização da demolição, transporte e disposição final de resíduos de obras de construção civil (entulho) e outros materiais contendo amianto ou asbesto. Disponível em: $<$ https://1fd39fc0-5440-4952-9d94-

0477e5c6c245.filesusr.com/ugd/f96098_8e284acea8c2 4db38b8addb36c04c6f0.pdf>. Acesso em: 11 abr. 2019.

INTERNACIONAL AGENCY FOR RESEARCH ON CANCER. Arsenic, Metals, Fibres, and Dusts: a review of human carcinogens. Lyon, France: WHO, 2012. (IARC monographs on the evaluation of the carcinogenic risk of chemicals to humans, Vol. 100C).

MENDES, R. Asbesto (amianto) e doença: revisão do conhecimento científico e fundamentação para uma urgente mudança da atual política brasileira sobre a questão. Revista de Saúde Pública, São Paulo, v. 17, n. 1, p. 7-29, 2001

PEREZ, M. A. M. (Org.). Troca limpa: manual de capacitação de trabalhadores para a retirada e o descarte de telhas e caixas d'água com amianto nas obras de melhorias habitacionais do setor 1 da Colônia Juliano Moreira. 1. ed. / organizado por Maria Ayara Mendo Perez, Flora d'El Rei Lopes Passos e Luis Carlos Soares Madeira Domingues. Rio de Janeiro: Fiocruz/Programa de Desenvolvimento do Campus Fiocruz da Mata Atlântica, 2013.

UNIVERSIDADE FEDERAL DA BAHIA.

Superintendência de Meio Ambiente e Infraestrutura. Telhados em Fibrocimento Unidades UFBA. Salvador, 2019. Não publicado. 